WORKING PAPER no. 13

\title{
The Welfare Effects of Liquidity Constraints
}

Tullio Jappelli and Marco Pagano

December 1998

Forthcoming in Oxford Economic Papers 


\title{
CSEF WORKING PAPER no. 13
}

\section{The Welfare Effects of Liquidity Constraints}

\author{
Tullio Jappelli* and Marco Pagano*
}

Forthcoming in Oxford Economic Papers

\begin{abstract}
We analyze the welfare implications of liquidity constraints for households in an overlapping generations model with growth. In a closed economy with exogenous technical progress, liquidity constraints reduce welfare if the economy is dynamically inefficient. But if it is dynamically efficient, some degree of financial repression is required to maximize steady-state utility, even though some generations are hurt in the transition. With endogenous technical progress, financial repression may increase welfare even along the transition path, thus leading to a Pareto improvement. In this case the optimal degree of financial repression increases as the economy grows.
\end{abstract}

JEL classification: E21, 016

KEYWORDS: saving, liquidity constraints, welfare

Authors' addresses: Tullio Jappelli, Dipartimento di Scienze Economiche, Università di Salerno, 84084 Fisciano (SA), Italy; e-mail: jappelli@synapsis.it

* CSEF, University of Salerno, and CEPR 


\section{Table of contents}

1. Introduction

2. The basic framework

3. Welfare analysis with exogenous growth

3.1 Steady-state equilibrium

3.2 Transitional effects of financial restriction

3.3 Fiscal policy

3.4 International capital mobility

4. Welfare analysis with endogenous growth

4.1 Steady-state equilibrium

4.2 Transitional effects of financial restriction

5. Conclusions

References

Appendix 


\section{Introduction}

A recent line of research argues forcefully that financial development affects the level and the allocation of real investment. Most contributions highlight that improvements in financial intermediation raise investment, by funneling saving to firms and allocating capital more efficiently among investment projects (for a survey, see Pagano, 1993). Even though most of these studies do not contain an explicit welfare analysis, they do carry the general implication that financial repression leads to inefficient outcomes. ${ }^{1}$

This literature focuses on lending and equity financing to firms, rather than on the supply of credit and insurance to households. But in the latter case financial repression can have quite different effects on capital accumulation: under plausible assumptions, aggregate saving rises if households are prevented from borrowing against their future incomes (Aiyagari, 1994) or from insuring against endowment risk or rate-of-return risk (Devereux and Smith, 1994). At the empirical level, indicators of constraints on households' borrowing are one of the major factors in explaining the international differences in private saving rates in the last three decades (Jappelli and Pagano, 1994).

Since reducing the availability of credit and insurance increases saving and investment, it is natural to ask if it can also increase welfare. In this paper we show that liquidity constraints on households have two opposite effects on households' utility. ${ }^{2}$ They distort the intertemporal consumption profile but they also raise households' permanent income by fostering capital accumulation. The benefit from higher capital accumulation can be large enough to outweigh the distortionary cost of liquidity constraints. Financial repression can increase welfare because the case considered is that of households with finite life. In an economy where households have infinite life, instead, liquidity constraints entail an unambiguous reduction in welfare, as shown by Aiyagari (1994) and Imrohoroglu (1989) in models with uninsurable income risk.

Restricting access to household credit is by no means the only way to foster capital accumulation in a model where households have finite life. Since Diamond's (1965) celebrated analysis, it has been known that national saving can be increased by intergenerational redistribution schemes such as a tax-financed re-

\footnotetext{
${ }^{1}$ Bencivenga and Smith (1992) and Roubini and Sala-i-Martin (1992) argue that reserve requirements - which act as a tax on banks - are beneficial only insofar as they raise the demand for currency and seigniorage: this allows the government to reduce the welfare cost of other distortionary taxes.

${ }^{2}$ Throughout the paper, the words "liquidity constraints" are used as synonimous of "borrowing constraints", as in much of the related literature.
} 
duction in public debt or a switch from a pay-as-you-go to a funded social security system. If taxes are lump-sum, these policies transfer resources from earlier to later generations without intertemporal distortions. Alternatively, higher capital accumulation can be achieved by stimulating saving via tax incentives or discouraging household debt via reduced incentives to borrow. The welfare cost of this policy - absent in the case of intergenerational redistributions - is a distortion in individual consumption profiles, which hurts equally present and future generations. The experiment that we perform in this paper belongs to this second class of policy instruments: we study the welfare consequences of introducing a quantity constraint on borrowing, which effectively makes the cost of borrowing infinite when the constraint is binding.

In Section 2 we set out the basic assumptions, an overlapping generations growth model where each household lives for three periods and is subject to a borrowing constraint when young. We analyze two versions of this model - one where technical progress is exogenous and the other in which an externality in production makes technical progress endogenous.

In Section 3 we show that when technical progress is exogenous and the economy is dynamically efficient, there is a degree of financial repression that maximizes steady-state utility. In the transition following a financial restriction, there are losers and winners: future generations eventually gain, but initial generations are hurt. The degree of financial repression that maximizes steady-state utility increases with the size of government spending: public consumption crowds out capital accumulation, raising the benefit from the forced saving due to liquidity constraints.

The results described so far hold in the absence of international capital mobility. With perfect capital mobility, however, the capital stock does not depend on domestic saving, because firms can draw on the world capital market: liquidity constraints distort the intertemporal consumption profile without affecting capital accumulation. Thus, in a small open economy it is desirable to lift financial restrictions in the domestic credit market for households. But what is optimal at national level is not optimal at world level: if each country liberalizes the domestic credit market, world saving and investment fall. Thus, a worldwide move toward capital mobility can lead to an inefficiently low steady-state capital stock.

In Section 4 we analyze a version of the model with endogenous technical progress, which arises from a production externality as in Romer (1989). Contrary to the model of Section 3, in the long run financial repression invariably increases welfare. The reason is that the higher saving induced by financial repression raises the steady-state growth rate of output, as opposed to its level. This implies that the trade-off between the loss from the intertemporal distortion and the gain from increased capital accumulation is non-stationary. That is, while the loss is the 
same for each generation, the welfare gain increases over time, and eventually dominates. Interestingly, with endogenous growth a financial restriction may raise the welfare of all generations, thus yielding a Pareto improvement.

There are two potentially important qualifiers to our analysis, if liquidity constraints reduce spending on education and trigger intergenerational transfers. First, liquidity constraints may discourage not only current consumption, as in our model, but also educational attainment. If young people are prevented from borrowing, they cannot afford the cost of schooling. Even if education is free, they cannot attend school because they must work for a living. De Gregorio (1996) models these effects, and shows that liquidity constraints foster saving, but reduce the accumulation of human capital. To the extent that human capital is an engine of growth, the effect of borrowing constraints on growth and welfare is a priori ambiguous. ${ }^{3}$ Second, altruistic parents may choose to alleviate the borrowing constraints of their children. To the extent that intergenerational transfers substitute for capital markets, households' horizon becomes effectively infinite, attenuating both the distortion induced by liquidity constraints and their impact on capital accumulation.

\section{The basic framework}

To illustrate the welfare effects of liquidity constraints, we resort to the overlapping generations model used in our previous work to study the relation between saving, growth and liquidity constraints (Jappelli and Pagano, 1994). We assume that individuals live for three periods, earning labor income only in the second period. Each individual supplies a single unit of labor inelastically. When young, individuals borrow to finance current consumption; when middle-aged they repay the loan taken out in the first period and save for retirement; and when old they consume the savings accumulated in the second period of their life. If markets are perfect, the young borrow the desired amount; we assume that with liquidity constraints, they can borrow at most a proportion $\phi$ of the present value of their lifetime income, for reasons that we do not model explicitly. Population is assumed to be stationary. The preferences of the generation born in a generic period $t$ are represented by a logarithmic utility function:

\footnotetext{
${ }^{3}$ The evidence indicates that proxies for liquidity constraints in the consumer credit and mortgage loan markets are positively correlated with productivity growth (Jappelli and Pagano, 1994), suggesting that the positive effect on saving outweighs the negative effect on human capital accumulation. De Gregorio (1996) finds more mixed evidence on this issue.
} 


$$
U_{t}=\ln c_{t, t}+\beta \ln c_{t, t+1}+\beta^{2} \ln c_{t, t+2}
$$

where $\beta$ is the discount factor and the first subscript indicates the generation, while the second refers to the timing of consumption. Households maximize utility subject to

$$
c_{t, t}+\frac{c_{t, t+1}}{R_{t+1}}+\frac{c_{t, t+2}}{R_{t+1} R_{t+2}} \leq \frac{e_{t+1}}{R_{t+1}}
$$

and

$$
c_{t, t} \leq \phi \frac{e_{t+1}}{R_{t+1}}
$$

where $e_{t+1}$ is real labor earnings at time $t+1$, and $R_{t+1}$ is the real interest factor between time $t$ and $t+1$. Equation (2) is the intertemporal budget constraint. Equation (3) is the borrowing constraint: the young can borrow at most a fraction $\phi$ of their discounted lifetime income. If the borrowing constraint (3) is not binding, the consumption of the young is

$$
c_{t, t}=\gamma \frac{e_{t+1}}{R_{t+1}}
$$

where $\gamma=1 /\left(1+\beta+\beta^{2}\right)$. If $\phi<\gamma$, instead, the borrowing constraint is binding, and first-period consumption is equal to the borrowing limit (the right-hand-side of 3). Thus the difference $\gamma-\phi$ measures the gap between the desired and actual consumption of the young, and provides a natural index of the degree of financial repression of households.

Technology is summarized by the aggregate production function

$$
Y_{t}=A_{t} K_{t}^{\alpha} L^{1-\alpha}
$$

where $Y_{t}$ is aggregate output, $K_{t}$ the aggregate capital stock and $L$ the (constant) labor force, which will be set equal to 1 hereafter. Capital depreciates completely within one period. The optimal consumption plan of an individual born at time $t$ is given by the following sequence of consumption levels:

$$
\begin{gathered}
c_{t, t}=\phi \frac{e_{t+1}}{R_{t+1}} \\
c_{t, t+1}=\frac{1-\phi}{1+\beta} e_{t+1} \\
c_{t, t+2}=\frac{\beta(1-\phi)}{1+\beta} e_{t+1} R_{t+2}
\end{gathered}
$$


Substituting these values into equation (1), we obtain the indirect utility function

$$
U_{t}=\ln \left(\phi \frac{e_{t+1}}{R_{t+1}}\right)+\beta \ln \left(\frac{1-\phi}{1+\beta} e_{t+1}\right)+\beta^{2} \ln \left(\frac{\beta(1-\phi)}{1+\beta} e_{t+1} R_{t+2}\right)
$$

Depending on how technical progress is modeled (the term $A_{t}$ in equation 4 ), one obtains as special cases the neoclassical exogenous growth model and the Romer (1989) endogenous growth model.

\section{Welfare analysis with exogenous growth}

One way of modeling growth is to assume Hicks-neutral technical progress, making total factor productivity $A_{t}$ an increasing function of time:

$$
A_{t}=A(1+\rho)^{t}
$$

where $\rho$ denotes the productivity growth rate. In this section we first analyze the effect of liquidity constraints in steady state, showing that perfect capital markets do not maximize the steady-state welfare of households in a dynamically efficient economy, but do in the dynamically inefficient case. We then analyze how the welfare of households changes along the transition to the new steady state equilibrium in response to an increase in the degree of financial repression. Finally, we consider how fiscal policy and international capital mobility alter the degree of financial repression that maximizes steady-state utility in this economy.

\subsection{Steady-state equilibrium}

Profit maximization by firms implies that the real wage and the interest factor are respectively determined by the following first-order conditions:

$$
e_{t}=(1-\alpha) A(1+\rho)^{t} K_{t}^{\alpha}
$$

and

$$
R_{t}=\alpha A(1+\rho)^{t} K_{t}^{\alpha-1}
$$

At each point in time, the aggregate wealth of the economy $\left(W_{t}\right)$ is the sum of the dissaving of young households and the saving of middle-aged households 
of the previous generation. Capital market equilibrium requires that aggregate wealth equal the subsequent period's demand for capital by firms $\left(K_{t+1}\right)$ :

$$
W_{t} \equiv \frac{(1-\phi) \beta}{1+\beta} e_{t}-\phi \frac{e_{t+1}}{R_{t+1}}=K_{t+1}
$$

Using equations (10) and (11) in the capital market equilibrium condition yields the difference equation:

$$
K_{t+1}=\frac{\beta(1-\phi) \alpha(1-\alpha) A(1+\rho)^{t}}{(1+\beta)[\alpha+\phi(1-\alpha)]} K_{t}^{\alpha}
$$

As is shown in Jappelli and Pagano (1994), in steady state the logarithm of the capital stock evolves according to:

$$
\ln K_{t}^{s s}=\frac{1}{1-\alpha} \ln \frac{\beta(1-\phi) \alpha(1-\alpha) A}{(1+\beta)[\alpha+\phi(1-\alpha)]}-\frac{\ln (1+\rho)}{(1-\alpha)^{2}}+\frac{\ln (1+\rho)}{1-\alpha} t
$$

This expression indicates that in steady state the capital stock grows at the rate $(1+\rho)^{\frac{1}{1-\alpha}}$ and is a decreasing function of $\phi$ : other things being equal, an economy with more stringent borrowing constraints will feature greater wealth and saving, because young consumers borrow less than the desired amount and the middle-aged have less to repay.

The positive effect of liquidity constraints on the capital stock brought out by equation (12) is particularly clear due to the assumption of logarithmic preferences. This assumption implies that the savings decisions of the middle aged are independent of the return to capital (see equation 6). With more general preferences, the effect of liquidity constraints on the capital stock can be reinforced or attenuated by the impact of the interest rate on the saving of the middle aged. If the substitution effect dominates the income effect, the saving of the middleaged increases in response to a higher interest rate. In this case, an increase in liquidity constraints, by decreasing the return to capital, lowers the saving of the middle aged and capital accumulation, thus attenuating the positive association between the severity of liquidity constraints and the level of the capital stock. If instead the income effect dominates, this relation would be reinforced.

Substituting into the indirect utility function (8) the optimal levels of consumption (equations 5, 6 and 7) and the equilibrium factor prices (10) and (11), and assuming that the economy is in steady state, one obtains the steady-state equilibrium level of utility (see the appendix for the derivation):

$$
U_{t}^{s s}=\ln \frac{\phi(1-\alpha)}{\alpha}+\beta \ln \frac{(1-\phi)(1-\alpha) A}{1+\beta}+\beta^{2} \ln \frac{\beta(1-\phi) \alpha(1-\alpha) A^{2}}{1+\beta}+
$$




$$
+\beta(1+2 \beta)(t+1) \ln (1+\rho)+\left[1+\alpha \beta+(2 \alpha-1) \beta^{2}\right] \ln K_{t+1}^{s s}
$$

Using equation (12) in (13) and differentiating with respect to $\gamma-\phi$, we obtain the marginal effect of a permanent change in the degree of financial repression:

$$
\frac{d U_{t}^{s s}}{d(\gamma-\phi)}=-\frac{d U_{t}^{s s}}{d \phi}=-\frac{1-\phi\left(1+\beta+\beta^{2}\right)}{\phi(1-\phi)}+\frac{1+\alpha \beta+\beta^{2}(2 \alpha-1)}{(1-\alpha)(1-\phi)[\alpha+\phi(1-\alpha)]}, \quad \forall t
$$

where the first equality follows from the fact that $\gamma$ is a constant. The derivative is time-invariant, reflecting the fact that in this model financial repression affects only the level, not the growth rate, of output and capital. The first term of the derivative measures the welfare loss from increasing the intertemporal distortions associated with liquidity constraints; it is accordingly negative.

The second term represents the welfare change associated with the increase in capital accumulation due to the fall in household debt. The sign of the second term depends on whether the economy would be dynamically efficient or inefficient in the absence of liquidity constraints. If the economy is dynamically inefficient, the second term too is negative. The capital stock already exceeds the level that maximizes steady-state consumption: financial repression is harmful because it forces the economy to accumulate even more capital. If instead the economy is dynamically efficient, the second term is positive, and the overall sign of the derivative ambiguous.

To prove this, note that when liquidity constraints are binding, i.e. when $\gamma-\phi>0$, the steady-state equilibrium interest rate is

$$
R^{s s}=\frac{(1+\beta)[\alpha+\phi(1-\alpha)]}{\beta(1-\alpha)(1-\phi)}(1+\rho)^{\frac{1}{1-\alpha}}
$$

which is a monotone and increasing function of $\phi$ (financial repression raises the capital stock and lowers its marginal productivity). The interest rate achieves its maximum value when capital markets are perfect, i.e. when $\phi=\gamma$ :

$$
\bar{R}^{s s}=\frac{1+\alpha \beta(1+\beta)}{\beta^{2}(1-\alpha)}(1+\rho)^{\frac{1}{1-\alpha}}
$$

In the absence of liquidity constraints, the economy is dynamically efficient if the equilibrium interest rate $\bar{R}^{s s}$ exceeds the golden rule interest rate, $R^{g r}=$ $(1+\rho)^{\frac{1}{1-\alpha}}$. This condition implies $[1+\alpha \beta(1+\beta)] / \beta^{2}(1-\alpha)>1$, so that the second term in (14) is positive and the overall sign of the derivative is ambiguous. Thus, in the dynamically efficient case, the forced saving induced by liquidity constraints is beneficial because it brings the economy closer to the golden rule, although at the cost of distorting the consumption path of each generation. 
As a result, in this case there is an optimal steady-state degree of financial repression: this corresponds to the value of $\phi$ that maximizes the steady-state utility of households, obtained by setting (14) equal to zero. Let us denote this value by $\phi^{*}$. This value is defined on the open interval $\left(\phi^{g r}, \gamma\right)$, where $\phi^{g r}$ is the value of $\phi$ that sets the economy on the golden rule path (implying $R^{s s}=$ $\left.R^{g r}\right)$ : setting $\phi$ below $\phi^{g r}$ would push the economy into the region of dynamic inefficiency, while at and above $\gamma$ the borrowing limit $\phi$ is no longer binding. ${ }^{4}$ It is easy to show that the optimal steady-state degree of financial repression, $\gamma-\phi^{*}$, is a decreasing function of $\beta$ and $\alpha$ : if households are patient (large $\beta$ ) or the marginal productivity of capital is high (large $\alpha$ ), the economy's capital stock is high even when households have easy access to credit. The benefits of a financial restriction in terms of additional accumulation are therefore relatively modest.

However if the economy is dynamically inefficient in the absence of liquidity constraints, then $\bar{R}^{s s}<R^{g r}$. In this case, the economy is dynamically inefficient when liquidity constraints are binding as well, because a lower $\phi$ is associated with an even higher capital stock. Repeating the foregoing argument, one finds that the second term of (14) is negative, reinforcing the effect of the first term. In a dynamically inefficient economy, removing liquidity constraints is an unambiguously welfare-improving policy: it eliminates an intertemporal distortion and it brings the capital stock closer to the path that maximizes steady-state consumption. The same result obtains for the knife-edge case in which the decentralized equilibrium coincides with the golden rule $\left(\bar{R}^{s s}=R^{g r}\right){ }^{5}$

To summarize, the steady-state analysis shows that when the economy is dynamically efficient with perfect capital markets, some degree of financial repression is optimal in steady state, even at the cost of increasing intertemporal distortions. When the economy is dynamically inefficient, imposing liquidity constraints always reduces welfare; this case, however, should be regarded more as a theoretical curiosity, rather than as a policy-relevant case in view of the evidence

\footnotetext{
${ }^{4}$ The second order condition for a maximum is satisfied, since the second derivative evaluated at $\phi=\phi^{*}$ is

$$
\frac{d^{2} U_{t}^{s s}}{d \phi^{2}}=\frac{\alpha+\phi^{2}(1-\alpha)\left(1+\beta+\beta^{2}\right)}{\phi^{2}(1-\phi)[\alpha+\phi(1-\alpha)]}<0 \quad \forall t
$$

${ }^{5}$ In this case, the term $[1+\alpha \beta(1+\beta)] / \beta^{2}(1-\alpha)=1$. This implies that the second term in (14) is equal to zero, so that the overall derivative is negative. Thus removing borrowing constraints is optimal if, in the absence of borrowing constraints, the economy would be following the golden rule.
} 
produced by Abel et al. (1989). The following section investigates the extent to which these statements also apply to the transitional phase after a financial restriction.

\subsection{Transitional effects of financial restriction}

Who gains and who loses from a financial restriction? Let us consider a policy experiment consisting in a permanent and unanticipated reduction in the fractional borrowing limit $\phi$, occurring at time 0 . We denote its new, lower value by $\phi^{\prime}$. The policy shock immediately reduces borrowing by the young and thus increases the current amount of saving (next period's capital stock). At time 0 factor prices are predetermined, but at time 1 the increase in the capital stock leads to a reduction in the interest rate and to an increase in the wage rate.

Whether or not the economy is dynamically efficient, the current old (born at time -2) are unaffected by the shock: their utility depends only on their capital income, and the latter is unaffected because at time 0 the interest rate is predetermined. However, the current middle-aged (born at time -1 ) invariably lose from the financial restriction: their current wage and the interest rate at which they repay their consumer loans are unaffected, but they anticipate a reduction in their future capital income, due to the fall in the interest rate at time 1. Therefore a financial repression is not a Pareto improvement.

Finally, the current young (born at time 0) suffer from the financial restriction if the economy is dynamically inefficient. If it is dynamically efficient, they may either gain or lose; in this case, the policy shock has four distinct effects on their welfare: they lose from the increased intertemporal distortion in consumption and from the lower interest rate when old but gain from the higher wage rate and the lower interest rate at which they repay their loans when middle-aged. All subsequent generations actually experience the same effects, but - as we shall see - their relative magnitude changes as the economy approaches the new steady state.

To evaluate the net effect on the welfare of current and future generations, we need to compute the transitional path of the stock of capital. In the appendix we show that in the period following the shock the capital stock grows according to

$$
\ln \left(K_{1} / K_{0}\right)=\frac{\ln (1+\rho)}{1-\alpha}+\ln \theta
$$


where

$$
\theta \equiv \frac{\alpha+\phi(1-\alpha)}{\alpha+\phi^{\prime}(1-\alpha)}>1
$$

The expression shows that in period 1 the growth rate exceeds its steady-state value because at time 0 the young borrow less, thus increasing the supply of capital. In period 2 there is a second positive shock to the growth rate: having borrowed less when young, the middle-aged save more, so that there is a further increase in the funds available for investment. The general law of motion of capital from period 2 onwards is:

$$
\ln \left(K_{n} / K_{n-1}\right)=\frac{\ln (1+\rho)}{1-\alpha}+\alpha^{n-1} \ln \theta+\alpha^{n-2} \ln \frac{1-\phi^{\prime}}{1-\phi} \quad \forall n>0
$$

Note that as $n \rightarrow \infty$, the growth rate of the economy reverts to its steady-state value, $(1+\rho)^{\frac{1}{1-\alpha}}$ : the acceleration of growth generated by the financial restriction is temporary. The last two equations can be used to compute the equilibrium utility level of each generation, starting with that born at time 0 , and to compare it with the utility that would have obtained if at time 0 the policy shock had not taken place. We denote the change in the welfare of generation $n$ induced by the financial restriction by $\Delta_{n}$. As shown in the appendix, for the generation born at time 0 the welfare change is

$$
\begin{gathered}
\Delta_{0}=\ln \frac{\phi^{\prime}}{\phi}+\beta(1+\beta) \ln \frac{1-\phi^{\prime}}{1-\phi}+\left(1+\alpha \beta+2 \alpha \beta^{2}-\beta^{2}\right) \ln \theta \\
-\beta^{2}(1-\alpha)\left(\alpha \ln \theta+\ln \frac{1-\phi^{\prime}}{1-\phi}\right)
\end{gathered}
$$

for any subsequent generation $n$, the welfare change is

$$
\begin{gathered}
\Delta_{n}=\ln \frac{\phi^{\prime}}{\phi}+\beta(1+\beta) \ln \frac{1-\phi^{\prime}}{1-\phi} \\
+\left(1+\alpha \beta+2 \alpha \beta^{2}-\beta^{2}\right)\left(\frac{1-\alpha^{n+1}}{1-\alpha} \ln \theta+\frac{1-\alpha^{n}}{1-\alpha} \ln \frac{1-\phi^{\prime}}{1-\phi}\right) \\
-\beta(1-\alpha)\left(\alpha^{n+1} \ln \theta+\alpha^{n} \ln \frac{1-\phi^{\prime}}{1-\phi}\right) \quad \forall n>0
\end{gathered}
$$

In the appendix we show that the sum of the first two terms of equations (18) and (19) is always negative. If the economy is dynamically inefficient, then the last two terms are also negative: all generations born at or after the policy shock 
lose from a financial restriction. ${ }^{6}$ If the economy is dynamically efficient, though, the sum of the last two terms is positive so that on balance the expression has an ambiguous sign. Moreover, since the last two terms grow over time, the overall sign of the expression can change, starting negative and turning positive at some critical value of $n$. The reason is that the distortionary effects of the financial restriction - the first two terms in (19) - are borne equally by all generations, while the countervailing benefits - the last two terms - are compounded over time: during the transition to the new steady state, financial restriction fosters more rapid capital accumulation and output growth relative to an economy with perfect credit markets. As $n \rightarrow \infty$ in (19), one obtains the effect of the financial repression on steady-state utility, i.e. the discrete counterpart of the derivative (14).

Figure 1 illustrates this intergenerational trade-off with a simulation. We set $\alpha=0.4$ and $\beta=0.7$ so that, if capital markets were perfect, the young would borrow $45.7 \%$ of their permanent income, i.e. $1 /(1+0.7+0.49)$. We then consider an array of policy experiments, all starting from a situation of perfect capital markets $(\phi \geq \gamma=45.7 \%)$. The horizontal axis gives the values of the new borrowing limit $\left(\phi^{\prime}\right)$ after the policy change. On the vertical axis, we plot the change in welfare of the generation born at the time of the shock $\left(\Delta_{0}\right)$ and of the subsequent 5 generations $\left(\Delta_{n}\right.$, for $\left.n=1, \ldots, 5\right)$.

For any given value of $\phi^{\prime}$, a line traces out the welfare change of the generations born at or after the shock: as noted above, later generations benefit more from the restriction. For most values of $\phi^{\prime}$ current and future generations gain. Later generations are hurt only if the financial restriction is extremely severe: if the borrowing limit is reduced to $5 \%$ (down from 45.7\%), generations 0 and 1 are hurt; for even lower values of $\phi^{\prime}$, all generations lose.

In the figure the degree of financial repression of households that maximizes steady-state welfare, $\phi^{*}$, corresponds to the highest point of the surface. For the parameter values used in Fig. 1, this optimal value of $\phi^{\prime}$ is $16.3 \%$. The figure may convey the impression that for $\phi^{\prime}=16.3 \%$ all the generations gain relative to the case of perfect capital markets $\phi \geq \gamma$. However, the figure does not show the adverse effect of financial repression on generation -1 , due to the lower interest rate in period 1 . Thus, we stress that moving from perfect capital markets to the optimal degree of financial repression $\phi^{*}$ does not constitute a Pareto improvement.

But the Pareto criterion is extremely demanding and need not forestall all

\footnotetext{
${ }^{6}$ Recall from the steady-state analysis that the economy is dynamically inefficient (with perfect capital markets) if and only if $1+\alpha \beta+2 \alpha \beta^{2}-\beta^{2}<0$. This implies that the third term in equation (19) is negative.
} 
policy intervention. Even if there is no obvious candidate for a social welfare function when households are not altruistically linked, any benevolent planner will try to trade off the interests of current and future generations by weighting their utilities appropriately. Unless no weight is assigned to future generations, some degree of financial repression will be desirable; the larger the weight given to future generations, the closer $\phi$ will be to its optimal steady-state value.

\subsection{Fiscal policy}

In this section we study the connection between government spending and the optimal steady-state value of $\phi$. In particular, we ask whether financial repression is more desirable after a permanent balanced-budget fiscal expansion. We assume that public consumption does not affect households' utility and grows at the growth rate of the economy:

$$
g_{t}=g_{0}(1+\rho)^{\frac{t}{1-\alpha}}
$$

The expenditure is financed by a proportional income tax and the budget is balanced in each period:

$$
g_{t}=\tau e_{t}
$$

Performing the same steps as in section 3.1, the logarithm of the steady-state capital stock can be written as:

$$
\ln K_{t}^{s s}=\frac{1}{1-\alpha} \ln \frac{\beta(1-\phi) \alpha(1-\alpha) A}{(1+\beta)[\alpha /(1-\tau)+\phi(1-\alpha)]}-\frac{\ln (1+\rho)}{(1-\alpha)^{2}}+\frac{\ln (1+\rho)}{1-\alpha} t
$$

This expression shows that the capital stock is a decreasing function of government spending. More public spending requires a higher tax rate $\tau$ for any given level of national income; the reduction in disposable income determines a fall in the level of saving and in the capital stock.

As before, the marginal effect of a permanent change in the degree of financial repression is found by differentiating steady-state utility with respect to $\gamma-\phi$ :

$$
\frac{d U_{t}^{s s}}{d(\gamma-\phi)}=-\frac{1-\phi\left(1+\beta+\beta^{2}\right)}{\phi(1-\phi)}+\frac{\left[1+\alpha \beta+\beta^{2}(2 \alpha-1)\right][1-\tau(1-\alpha)]}{(1-\alpha)(1-\phi)[\alpha+\phi(1-\alpha)(1-\tau)}
$$

which reduces to (14) for $\tau=0$. In the dynamically efficient case, equating this expression to zero yields an implicit expression for the optimal steady-state degree of financial repression, $\gamma-\phi^{*}$ : 


$$
\frac{d U_{t}^{s s}}{d(\gamma-\phi)}=F\left(\gamma-\phi^{*} ; \beta, \alpha, \tau\right)=0
$$

We are interested in knowing how an increase in the size of the government affects the optimal degree of financial repression. Total differentiation of this first-order condition yields

$$
\frac{d\left(\gamma-\phi^{*}\right)}{d \tau}=\frac{\partial F / \partial \tau}{\partial F / \partial \phi^{*}}>0
$$

since $\partial F / \partial \tau$ and $\partial F / \partial \phi^{*}$ are both negative.

Thus an increase in government spending is associated with an increase in the optimal degree of financial repression. The reason is that the increase in government spending crowds out capital accumulation, pushing the economy further away from the golden rule growth path. At the margin, this raises the benefit of the forced saving induced by liquidity constraints. Therefore, countries that choose to devote a large share of resources to public consumption should compensate the implied crowding out of investment by restricting households' access to credit.

\subsection{International capital mobility}

If the assumption of a closed economy is dropped, the results of our welfare analysis change considerably. In a small open economy with perfect capital mobility, the domestic capital stock is determined by the world interest rate $R_{w}$, not by domestic saving. In fact, from equation (11) the capital stock evolves according to

$$
K_{t}=\left(\frac{\alpha A(1+\rho)^{t}}{R_{w}}\right)^{\frac{1}{1-\alpha}}
$$

In this economy a financial restriction distorts the intertemporal allocation of resources without affecting the equilibrium level of capital, output and factor prices. As a result, the restriction reduces the welfare of all generations, not only in the transition but also in steady state. The change in the welfare level of a generic generation $n$ is

$$
\Delta_{n}=\ln \frac{\phi^{\prime}}{\phi}+\beta(1+\beta) \ln \frac{1-\phi^{\prime}}{1-\phi}
$$


which corresponds to the first two terms of (19). As is shown in the appendix, this expression is unambiguously negative: in a small open economy, it is always optimal to liberalize internal credit markets. Thus, an interesting normative implication of our model is that the removal of capital controls should be accompanied by the liberalization of the market for household debt. This indeed appears to have been the experience of several European countries during the eighties: Spain, Ireland, Italy and the Scandinavian countries considerably softened regulatory obstacles and barriers to competition in the consumer credit and mortgage markets shortly after liberalizing capital flows.

A concurrent explanation for the simultaneous lifting of capital controls and credit markets restrictions is that there is no point in restraining lending to domestic firms and consumers once they can freely borrow from foreign banks. The only effect would be a massive disintermediation of domestic banks. By the same token, it would be hard to liberalize the market for corporate loans without removing liquidity constraints on households, since this would open the door to arbitrage opportunities. For instance, many households could increase their current consumption by borrowing via family-owned businesses.

While from the standpoint of each individual country liberalizing the market for household debt enhances the welfare of citizens, this policy is not optimal if one considers its effects on the world supply of saving in the wake of a generalized move toward free capital movement. For the world economy as a whole, naturally, the results obtained for the closed economy in Section 3.2 are still valid: in the dynamically efficient case, there is an optimal steady-state degree of financial repression at the world level.

With perfect capital mobility each government perceives that its country's saving makes a small, perhaps negligible, contribution to global capital accumulation and will be accordingly reluctant to impose on its citizens the cost of a forced saving policy to raise its contribution to the world capital stock. Each government therefore fails to internalize the effect of its decisions on the world supply of saving: this inefficiency can be avoided only by international policy coordination.

\section{Welfare analysis with endogenous growth}

The trade-off between the loss from distorting intertemporal choices and the gain from increasing capital accumulation also obtains when productivity growth is endogenous. However, unlike the case of exogenous growth, the trade-off is non- 
stationary. While the distortionary loss associated with the borrowing constraint is the same for all generations, the welfare gain of each generation increases over time, because tighter liquidity constraints raise the steady-state growth rate - as opposed to the level of capital. This insight applies to the steady state comparison of two economies with different values of $\phi$, as well as to the analysis of a policy experiment where $\phi$ is permanently and unexpectedly reduced.

Suppose that $A_{t}$, rather than being an exogenous process, is given by

$$
A_{t}=A K_{t}^{\eta}
$$

Thus, the state of technology evolves not as a function of time (as in the previous section), but rather as a function of the aggregate level of capital. Equation (20) can be motivated by the assumption of production externalities. Individual firms behave competitively and maximize profits taking $A_{t}$ as given. This leads to an aggregate production function featuring increasing returns:

$$
Y_{t}=A K_{t}^{\alpha+\eta}
$$

where the degree of increasing returns depends on the value of $\eta$. Assuming that $\alpha+\eta=1$, as in Romer (1989), production is a linear function of capital, that is, $Y_{t}=A K_{t}$. In this case the equilibrium factor prices are

$$
e_{t}=(1-\alpha) A K_{t}
$$

and

$$
R=\alpha A
$$

The capital market equilibrium condition is

$$
W_{t} \equiv \frac{(1-\phi) \beta}{1+\beta} e_{t}-\phi \frac{e_{t+1}}{R_{t+1}}=K_{t+1} \equiv \frac{\beta(1-\phi) \alpha(1-\alpha) A}{(1+\beta)[\alpha+\phi(1-\alpha)]} K_{t}
$$

which implies that the steady-state growth factor is

$$
g=\frac{\beta(1-\phi) \alpha(1-\alpha) A}{(1+\beta)[\alpha+\phi(1-\alpha)]}
$$

liquidity constraints increase the growth rate, not the level of the capital stock as in the exogenous growth version of the model.

Substituting the equilibrium factor prices (21) and (22) in equation (1) one obtains the steady-state utility of generation $t$ :

$$
U_{t}^{s s}=\ln \frac{\phi(1-\alpha)}{\alpha}+\beta \ln \frac{(1-\phi)(1-\alpha) A}{1+\beta}+\beta^{2} \ln \frac{\beta(1-\phi) \alpha(1-\alpha) A^{2}}{1+\beta}+
$$




$$
+\left(1+\beta+\beta^{2}\right) \ln K_{t+1} \quad \forall t
$$

where

$$
\ln K_{t+1}=\ln K_{0}+(\ln g)(t+1)
$$

As in the previous section, we first examine the effect of $\phi$ on steady-state utility and then consider the transitional effects of a financial restriction.

\subsection{Steady-state equilibrium}

At the margin the welfare effect of a permanent increase in the degree of financial repression, as measured by $\gamma-\phi$, is

$$
\begin{aligned}
& \frac{d U_{t}^{s s}}{d(\gamma-\phi)}=-\frac{1-\phi\left(1+\beta+\beta^{2}\right)}{\phi(1-\phi)}+\left(1+\beta+\beta^{2}\right) \frac{d \ln K_{t+1}}{d \phi}= \\
& =-\frac{1-\phi\left(1+\beta+\beta^{2}\right)}{\phi(1-\phi)}+\frac{1+\beta+\beta^{2}}{(1-\phi)[\alpha+\phi(1-\alpha)]}(t+1) \quad \forall t
\end{aligned}
$$

where the derivative is taken holding $K_{0}$ constant. The expression shows that when growth is endogenous financial repression still has an ambiguous impact on welfare. But in this case the second term of the derivative is unambiguously positive, as we found in the dynamically efficient case with exogenous growth. This should not be surprising, in light of the fact that one-sector endogenous growth models always feature capital under-accumulation. ${ }^{7}$ While the negative term of the derivative is constant, the positive one is non-stationary: as the economy grows, the marginal effect of the higher saving induced by liquidity constraints increases, and eventually outweighs the first term. Intuitively, since financial repression promotes growth, the resources controlled by each generation compound at a higher rate: this positive effect is proportionately larger for later generations than earlier ones, while the negative effect of tightening the constraint affects all generations in the same way.

\footnotetext{
${ }^{7}$ King and Ferguson (1993) and Azariadis and Reichlin (1996) show that balanced growth equilibria are always dynamically efficient in one-sector competitive models with endogenous growth.
} 


\subsection{Transitional effects of a financial restriction}

As in Section 3.2, assume that the borrowing limit $\phi$ is reduced to a lower level $\phi^{\prime}$ at time 0 . The main difference from the case of exogenous growth is that here a financial restriction can lead to a Pareto improvement, strengthening the case for a forced saving policy. As in the exogenous growth case, the current old (generation -2) are unaffected by the policy change; in contrast to that case, however the middle-aged (generation -1) are also unaffected by the credit restriction: since the interest rate is constant at the level $\alpha A$, their capital income when old is not reduced by a fall in the interest rate as in the exogenous growth model. Subsequent generations may all gain, as we show below.

Denote the growth factor of the capital stock at time $n$ : $K_{n} / K_{n-1}=g_{n}$. In the appendix we show that the growth rate increases twice from its initial steady state value $g$ :

$$
g=g_{0}<g_{1}<g_{2}
$$

The first increase in growth in period 1 is fueled by the lower debt of the young; the second, in period 2, by the higher savings of the middle-aged; $g_{2}$ is the new steady-state growth factor.

Using this sequence of growth factors, we evaluate the utility of the generations born before and after the shock. As in Section 3.2, we define the change in the welfare of generation $n$ due to the financial restriction by $\Delta_{n}=U_{n}-\bar{U}_{n}$. In the appendix we prove that generation -1 is unaffected by the shock $\left(\Delta_{-1}=0\right)$, while for all subsequent generations the welfare change is

$\Delta_{n}=\ln \frac{\phi^{\prime}}{\phi}+\beta(1+\beta) \ln \frac{1-\phi^{\prime}}{1-\phi}+\left(1+\beta+\beta^{2}\right)\left[(n+1) \ln \theta+n \ln \frac{1-\phi^{\prime}}{1-\phi}\right] \quad \forall n \geq 0$

The first two terms are identical to those of equation (19) in Section 3.2: they are unambiguously negative and capture the distortionary effect of the credit restriction. The last term is positive and grows over time, reflecting the beneficial effect of the higher growth rate.

To gauge the impact of a financial restriction, we evaluate $\Delta_{n}$ for the same set of parameter values used in Fig. 1. The results are plotted in Fig. 2. The figure shows that at most the financial restriction hurts only generations 0 and 1 and benefits all subsequent ones. Indeed, if $\phi$ is reduced to any value above $11.6 \%$, the welfare of all generations increases: within this range, a financial restriction is a Pareto improvement. If $\phi$ is further reduced to values between 11.6 and 1\%, the current generation is hurt, but the welfare of all others increases. The second generation is damaged only if one performs a drastic financial restriction in which borrowing is virtually prohibited (reduced to $0.1 \%$ of permanent income). 
This section has shown that financial repression can yield a Pareto gain for a wide range of parameter values. What prevents households from achieving this gain by private contracting? The "market failure" that leads to inefficiently low saving originates from the production externality that characterizes this economy. When choosing investment, each firm takes the

aggregate capital stock as given, neglecting that its own investment will lead to a higher capital stock and therefore to higher productivity. As a result, the decentralized outcome features an inefficiently low demand for capital. Borrowing constraints raise the equilibrium capital stock, offsetting the externality and increasing welfare. The same outcome could be achieved by a cooperative arrangement whereby current and future generations agree to save more than the amount warranted by their private incentives: clearly, such a sophisticated social contract is very hard for individuals with finite horizons to implement. One can interpret the financial repression of young households as a device employed by an infinitely-lived institution to enforce such a social contract.

As noted in section 1, constraining household borrowing is just one among many ways to increase national saving and the capital stock: any policy intervention that transfers wealth from the old to the young generations can achieve this result, and so can a plan of saving incentives or investment subsidies. In the endogenous growth model of this section, any of these policies may yield a Pareto improvement. Saving incentives also share with liquidity constraints the feature of distorting intertemporal choices. Empirically, however, there is very limited evidence that saving incentives raise national saving, since the private sector response depends on the balance between income and substitution effects and tax incentives generally lower government saving. Furthermore, liquidity constraints do not entail a cost in terms of government resources. For these reasons, liquidity constraints may be a more effective instrument in raising national saving: the evidence in Jappelli and Pagano (1994) suggests that they indeed raise national saving significantly.

\section{Conclusions}

In this paper we show that in models with finite horizons liquidity constraints on households have two opposite effects on welfare: they force the consumption of the young below the unconstrained level but raise their permanent income by fostering capital accumulation.

When productivity growth is exogenous, the trade-off arises only if the econ- 
omy would be dynamically efficient in the absence of liquidity constraints: if under perfect markets the interest rate exceeds the growth rate, the forced saving induced by liquidity constraints brings the economy closer to the golden rule, although at the cost of distorting the consumption path of each generation. In this case there is a degree of financial repression that maximizes steady-state utility. Even though a financial restriction hurts the generation born in the period before the policy shock, simulations show that for reasonable parameter values all subsequent generations gain. So a benevolent planner who cares about the welfare of all generations will generally find that some degree of financial repression is desirable.

The trade-off between the loss from distorting intertemporal choices and the gain from increasing capital accumulation also appears when productivity growth is endogenous. In this case the trade-off is non-stationary. While the distortionary loss associated with the borrowing constraint is the same for all generations, the welfare gain of each generation increases over time, because tighter liquidity constraints raise steady-state growth. This insight applies to the steady state comparison of two economies with different borrowing limits, as well as to a permanent and unexpected financial restriction. Simulations show that for a wide range of parameter values a financial restriction may lead to a Pareto improvement.

Our analysis weakens the case for liberalizing the market for household debt. So far the liberalization of this market has been widely regarded as beneficial because it enlarges consumers' opportunity sets. This view neglects that these policies lower national saving, investment and growth, and thereby reduce the standard of living of current and future generations. This point should be recognized by policy-makers, who are currently confronted by a worldwide shortage of saving due to the combination of high government deficits, a growing demand for capital by the dynamic economies of Asia, Latin America and Eastern Europe, and a fall in private saving in OECD countries. The latter can be attributed in part to the recent liberalization of the consumer credit and mortgage loan markets.

Acknowledgment: This paper has benefited from comments by Daniele Checchi, Luigi Guiso, Pietro Reichlin and seminar participants at the Bank of Italy, CentER, IGIER, University College London, Università di Milano, Universität Mannheim, and the CEPR Conference on "International Perspectives on the Macroeconomic and Microeconomic Implications of Financing Constraints". We acknowledge financial support from the Italian National Research Council (CNR) and the Ministry for Universities and Scientific and Technological Research (MURST). 


\section{References}

[1] Abel, A., N. G. Mankiw, L. H. Summers, and R. J. Zeckhauser (1989). 'Assessing Dynamic Efficiency: Theory and Evidence', The Review of Economic Studies, 56, 1-20.

[2] Aiyagari, R. S. (1994). 'Uninsured Idiosyncratic Risk and Aggregate Saving', Quarterly Journal of Economics, 109, 659-84.

[3] Azariadis, C., and P. Reichlin (1996). 'Increasing Returns and Crowdingout', Journal of Economic Dynamics and Control, 20, 847-77.

[4] Bencivenga, V. R., and B. D. Smith (1992). 'Deficits, Inflation and the Banking System in Developing Countries: the Optimal Degree of Financial Repression', Oxford Economic Papers, 44, 767-90.

[5] De Gregorio, J. (1996). 'Borrowing Constraints, Human Capital Accumulation, and Growth', Journal of Monetary Economics, 32, 79-104.

[6] Devereux, M. B., and G. W. Smith (1994). 'International Risk Sharing and Economic Growth', International Economic Review, 35, 535-50.

[7] Diamond, P. A. (1965). 'National Debt in a Neoclassical Growth Model', American Economic Review, 55, 1126-50.

[8] Îmrohoroglu, A. (1989). 'Cost of Business Cycles with Indivisibilities and Liquidity Constraints', Journal of Political Economy, 97, 1364-83.

[9] Jappelli, T., and M. Pagano (1994). 'Saving, Growth, and Liquidity Constraints', Quarterly Journal of Economics, 109, 83-109.

[10] King, I., and D. Ferguson (1993). 'Dynamic Inefficiency, Endogenous Growth, and Ponzi Games', Journal of Monetary Economics, 32, 79-104.

[11] Pagano, M. (1993). 'Financial Markets and Growth: an Overview', European Economic Review, 37, 613-22.

[12] Romer, P. (1989). 'Capital Accumulation in the Theory of Long-run Growth', in R. J. Barro (ed.), Modern Business Cycle Theory, Harvard University Press, Cambridge, MA.

[13] Roubini, N., and X. Sala-i-Martin (1992). 'Financial Repression and Economic Growth', Journal of Development Economics, 39, 5-30. 


\section{Appendix}

\section{A Derivation of steady-state equilibrium utility}

We first rewrite the optimal levels of consumption in terms of the capital stock by substituting the equilibrium factor prices (10) and (11) into equations (5), (6) and (7):

$$
\begin{gathered}
\frac{e_{t+1}}{R_{t+1}}=\frac{1-\alpha}{\alpha} K_{t+1} \\
e_{t+1}=(1-\alpha) A(1+\rho)^{t+1} K_{t+1}^{\alpha} \\
e_{t+1} R_{t+2}=\alpha(1-\alpha) A^{2}(1+\rho)^{2 t+3} K_{t+1}^{\alpha} K_{t+2}^{\alpha-1}
\end{gathered}
$$

In steady state, $K_{t+2}^{s s}=(1+\rho)^{\frac{1}{1-\alpha}} K_{t+1}^{s s}$ and the third expression can be written as

$$
e_{t+1} R_{t+2}=\alpha(1-\alpha) A^{2}(1+\rho)^{2(t+1)}\left(K_{t+1}^{s s}\right)^{2 \alpha-1}
$$

Substituting these expressions in the indirect utility function (8) and collecting terms, one obtains:

$$
\begin{gathered}
U_{t}^{s s}=\ln \frac{\phi(1-\alpha)}{\alpha}+\beta \ln \frac{(1-\phi)(1-\alpha) A}{1+\beta}+\beta^{2} \ln \frac{\beta(1-\phi) \alpha(1-\alpha) A^{2}}{1+\beta}+ \\
+\beta(t+1) \ln (1+\rho)+\beta^{2}[\ln (1+\rho)] 2(t+1)+\ln K_{t+1}^{s s}+\beta\left[\ln \left(K_{t+1}^{s s}\right)^{\alpha}\right]+\beta^{2}\left[\ln \left(K_{t+1}^{s s}\right)^{2 \alpha-1}\right]= \\
\ln \frac{\phi(1-\alpha)}{\alpha}+\beta \ln \frac{(1-\phi)(1-\alpha) A}{1+\beta}+\beta^{2} \ln \frac{\beta(1-\phi) \alpha(1-\alpha) A^{2}}{1+\beta}+ \\
+\beta(1+2 \beta)(t+1) \ln (1+\rho)+\left[1+\alpha \beta+(2 \alpha-1) \beta^{2}\right] \ln K_{t+1}^{s s}
\end{gathered}
$$

which is the steady-state equilibrium level of utility in equation (13). 


\section{B The transition with exogenous growth}

\section{B.1 Derivation of the growth rates}

The capital market equilibrium condition immediately before the financial restriction (time -1 ), at the time of the restriction (time 0 ), and $n$ periods later (time $n>0$ ) are respectively

$$
\begin{gathered}
(1+\beta)[\alpha+\phi(1-\alpha)] K_{0}=\beta(1-\phi) \alpha(1-\alpha) A(1+\rho)^{-1} K_{-1}^{\alpha} \\
(1+\beta)\left[\alpha+\phi^{\prime}(1-\alpha)\right] K_{1}=\beta(1-\phi) \alpha(1-\alpha) A(1+\rho)^{-1} K_{0}^{\alpha} \\
(1+\beta)\left[\alpha+\phi^{\prime}(1-\alpha)\right] K_{n+1}=\beta\left(1-\phi^{\prime}\right) \alpha(1-\alpha) A(1+\rho)^{-1} K_{n}^{\alpha}
\end{gathered}
$$

Dividing (30) by (29), taking logarithms and recalling that in period 0 the growth rate is $\ln \left(K_{0} / K_{-1}\right)=[\ln (1+\rho)] /(1-\alpha)$, one obtains equation (16) in the text. Similarly, dividing equation (31) for $n=1$ by (30), taking logs and using (16), one obtains the growth factor in period 2 :

$$
\ln \left(K_{2} / K_{1}\right)=\frac{\ln (1+\rho)}{1-\alpha}+\alpha \ln \theta+\ln \frac{1-\phi^{\prime}}{1-\phi}
$$

Recursively, one obtains equation (17) in the text.

\section{B.2 Derivation of the welfare levels}

Denote by $U_{t}$ the utility of the generation born at time $t=0,1, \ldots$, when at time 0 there is a financial restriction, and by $\bar{U}_{t}$ the utility of the same generation if at time 0 no restriction occurs. The corresponding capital stocks in the two regimes are denoted by $K_{t}$ and $\bar{K}_{t}$. Substituting (11) and (10) in the utility function (8) in the text and rearranging, one obtains

$$
\begin{gathered}
U_{0}=\ln \frac{\phi^{\prime}(1-\alpha)}{\alpha}+\beta \ln \frac{\left(1-\phi^{\prime}\right)(1-\alpha) A}{1+\beta}+\beta^{2} \ln \frac{\beta\left(1-\phi^{\prime}\right) \alpha(1-\alpha) A^{2}}{1+\beta} \\
+\left[\beta(t+1)+\beta^{2}(2 t+3)\right] \ln (1+\rho)-\beta^{2}(1-\alpha) \ln \left(K_{2} / K_{1}\right) \\
\quad+\left(1+\alpha \beta+2 \alpha \beta^{2}-\beta^{2}\right)\left[\ln \left(K_{1} / K_{0}\right)+\ln K_{0}\right]
\end{gathered}
$$

The corresponding expression in the regime without financial restriction is 


$$
\begin{gathered}
\bar{U}_{0}=\ln \frac{\phi(1-\alpha)}{\alpha}+\beta \ln \frac{(1-\phi)(1-\alpha) A}{1+\beta}+\beta^{2} \ln \frac{\beta(1-\phi) \alpha(1-\alpha) A^{2}}{1+\beta} \\
+\left[\beta(t+1)+\beta^{2}(2 t+3)\right] \ln (1+\rho)-\beta^{2}(1-\alpha) \ln \left(\bar{K}_{2} / \bar{K}_{1}\right) \\
+\left(1+\alpha \beta+2 \alpha \beta^{2}-\beta^{2}\right)\left[\ln \left(\bar{K}_{1} / \bar{K}_{0}\right)+\ln \bar{K}_{0}\right]
\end{gathered}
$$

Since the change in $\phi$ occurs at time 0 , the capital stock is predetermined and $K_{0}=\bar{K}_{0}$. If no financial restriction occurs, the growth rate is always equal to its steady-state value: $\ln \left(\bar{K}_{n+1} / \bar{K}_{n}\right)=[\ln (1+\rho)] /(1-\alpha), \forall n$. Substituting the growth rates derived above in (32) and (33), and taking the difference $\Delta_{0} \equiv$ $U_{0}-\bar{U}_{0}$, one obtains equation (18) in the text.

Similarly, the utility of generation 1 after the financial restriction is

$$
\begin{aligned}
U_{1}= & \ln \frac{\phi^{\prime}(1-\alpha)}{\alpha}+\beta \ln \frac{\left(1-\phi^{\prime}\right)(1-\alpha) A}{1+\beta}+\beta^{2} \ln \frac{\beta\left(1-\phi^{\prime}\right) \alpha(1-\alpha) A^{2}}{1+\beta} \\
& +\left[\beta(t+2)+\beta^{2}(2 t+4)\right] \ln (1+\rho)-\beta^{2}(1-\alpha) \ln \left(K_{3} / K_{2}\right) \\
& +\left(1+\alpha \beta+2 \alpha \beta^{2}-\beta^{2}\right)\left[\ln \left(K_{2} / K_{1}\right)+\ln \left(K_{1} / K_{0}\right)+\ln K_{0}\right]
\end{aligned}
$$

The corresponding expression in the regime without financial restriction is

$$
\begin{aligned}
\bar{U}_{1}= & \ln \frac{\phi(1-\alpha)}{\alpha}+\beta \ln \frac{(1-\phi)(1-\alpha) A}{1+\beta}+\beta^{2} \ln \frac{\beta(1-\phi) \alpha(1-\alpha) A^{2}}{1+\beta} \\
& +\left[\beta(t+2)+\beta^{2}(2 t+4)\right] \ln (1+\rho)-\beta^{2}(1-\alpha) \ln \left(\bar{K}_{3} / \bar{K}_{2}\right) \\
& +\left(1+\alpha \beta+2 \alpha \beta^{2}-\beta^{2}\right)\left[\ln \left(\bar{K}_{2} / \bar{K}_{1}\right)+\ln \left(\bar{K}_{1} / \bar{K}_{0}\right)+\ln \bar{K}_{0}\right]
\end{aligned}
$$

Substituting the growth factors (16) and (17) in the last two expressions and taking their difference yields

$$
\begin{aligned}
\Delta_{1}=\ln \frac{\phi^{\prime}}{\phi}+\beta(1+\beta) \ln & \frac{1-\phi^{\prime}}{1-\phi}+\left(1+\alpha \beta+2 \alpha \beta^{2}-\beta^{2}\right)\left((1+\alpha) \ln \theta+\ln \frac{1-\phi^{\prime}}{1-\phi}\right) \\
& -\beta(1-\alpha)\left(\alpha^{2} \ln \theta+\alpha \ln \frac{1-\phi^{\prime}}{1-\phi}\right)
\end{aligned}
$$

Iterating these steps produces the law of motion of $\Delta_{n}$ (equation (19) in the text), namely:

$$
\Delta_{n}=\ln \frac{\phi^{\prime}}{\phi}+\beta(1+\beta) \ln \frac{1-\phi^{\prime}}{1-\phi}+\left(1+\alpha \beta+2 \alpha \beta^{2}-\beta^{2}\right)\left(\frac{1-\alpha^{n+1}}{1-\alpha} \ln \theta+\frac{1-\alpha^{n}}{1-\alpha} \ln \frac{1-\phi^{\prime}}{1-\phi}\right)
$$




$$
-\beta(1-\alpha)\left(\alpha^{n+1} \ln \theta+\alpha^{n} \ln \frac{1-\phi^{\prime}}{1-\phi}\right), \quad \forall n>1
$$

The sum of the first two terms of $\Delta_{n}$ is negative for $\phi^{\prime}<\phi \leq \gamma$, because the sum equals 0 for $\phi=\phi^{\prime}$ and achieves a unique maximum at $\phi^{\prime}=\gamma$. The sum of the last two terms is positive in the dynamically efficient case (where $1+\alpha \beta+2 \alpha \beta^{2}-\beta^{2}>0$ ), as can be seen by writing them as:

$$
\begin{gathered}
\left(1+\alpha \beta+2 \alpha \beta^{2}-\beta^{2}\right)\left(\frac{1-\alpha^{n}}{1-\alpha} \ln \theta+\frac{1-\alpha^{n-1}}{1-\alpha} \ln \frac{1-\phi^{\prime}}{1-\phi}\right) \\
+[(1-\beta)(1+\alpha+\beta)+\alpha \beta(\alpha+2 \beta)]\left(\alpha^{n} \ln \theta+\alpha^{n-1} \ln \frac{1-\phi^{\prime}}{1-\phi}\right)
\end{gathered}
$$

\section{The transition with endogenous growth}

\section{C.1 Derivation of the growth rates}

At the time of the policy shock the capital market equilibrium condition is

$$
(1+\beta)[\alpha+\phi(1-\alpha)] g_{0}=\beta(1-\phi) \alpha(1-\alpha) A
$$

In period 0 , it becomes

$$
(1+\beta)\left[\alpha+\phi^{\prime}(1-\alpha)\right] g_{1}=\beta(1-\phi) \alpha(1-\alpha) A
$$

and at time 1 and in all subsequent periods it becomes:

$$
(1+\beta)\left[\alpha+\phi^{\prime}(1-\alpha)\right] g_{2}=\beta\left(1-\phi^{\prime}\right) \alpha(1-\alpha) A
$$

This sequence of capital market equilibrium conditions implies the inequalities in (27). 


\section{C.2 Derivation of the welfare levels}

The utility of the generation born in the period before the restriction is

$$
\begin{gathered}
U_{-1}=\ln \frac{\phi(1-\alpha)}{\alpha}+\beta \ln \frac{(1-\phi)(1-\alpha) A}{1+\beta}+\beta^{2} \ln \frac{\beta(1-\phi) \alpha(1-\alpha) A^{2}}{1+\beta}+ \\
+\left(1+\beta+\beta^{2}\right) \ln K_{0}
\end{gathered}
$$

and that of the subsequent generations is

$$
\begin{gathered}
U_{n}=\log \frac{\phi^{\prime}(1-\alpha)}{\alpha}+\beta \log \frac{\left(1-\phi^{\prime}\right)(1-\alpha) A}{1+\beta}+\beta^{2} \log \frac{\beta\left(1-\phi^{\prime}\right) \alpha(1-\alpha) A^{2}}{1+\beta}+ \\
+\left(1+\beta+\beta^{2}\right)\left[\ln K_{0}+\ln g_{1}+n \ln g_{2}\right] \quad \forall n \geq 0
\end{gathered}
$$

If $\phi$ does not change at date 0 , the respective welfare levels are given by the expression:

$$
\begin{gathered}
\bar{U}_{n}=\ln \frac{\phi(1-\alpha)}{\alpha}+\beta \ln \frac{(1-\phi)(1-\alpha) A}{1+\beta}+\beta^{2} \ln \frac{\beta(1-\phi) \alpha(1-\alpha) A^{2}}{1+\beta}+ \\
+\left(1+\beta+\beta^{2}\right)\left[\ln K_{0}+(\ln g)(n+1)\right] \quad \forall n
\end{gathered}
$$

As can be seen by subtracting (42) from (40), the welfare of generation -1 is unaffected by the restriction $\left(\Delta_{-1}=U_{-1}-\bar{U}_{-1}=0\right)$. Subtracting (41) from (40) and substituting the growth factors $g_{1}$ and $g_{2}$ from (38) and (39), one finds the welfare change for subsequent generations, that is, equation (28) in the text. 
Figure 1. The welfare effect of a financial restriction with exogenous growth

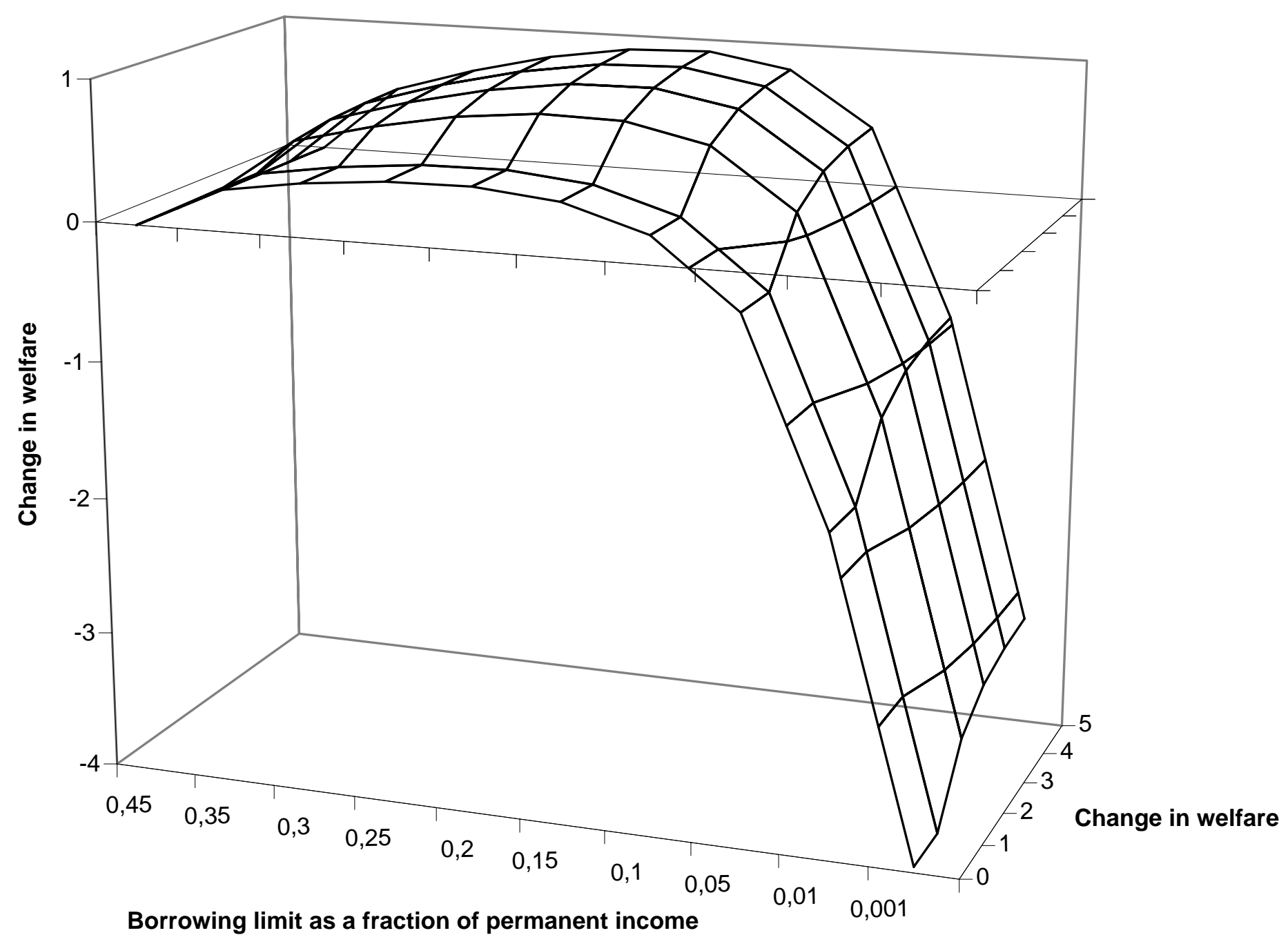


Figure 2. The welfare effect of a financial restriction with endogenous growth

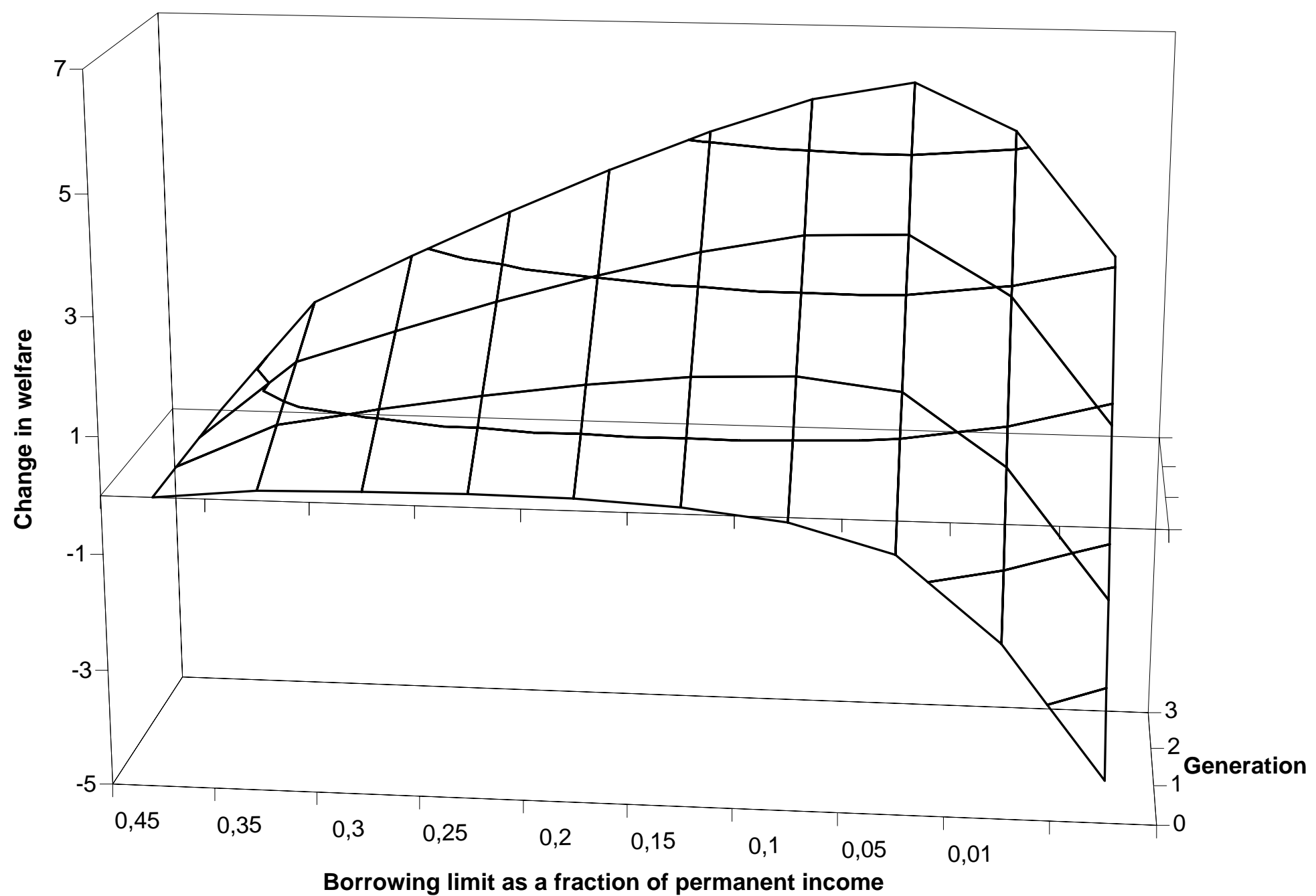

